\title{
Infantile idiopathic scoliosis: surgical treatment in rapidly progressive cases
}

D Lawniczak ${ }^{*}$, T Kotwicki

From 8th International Conference on Conservative Management of Spinal Deformities and SOSORT 2011 Annual Meeting

Barcelona, Spain. 19-21 May 2011

\section{Purpose}

To present 4 cases ( 5 curves) of infantile scoliosis in children initially managed with corrective brace and physiotherapy. All finally underwent surgical treatment.

\section{Materilas and methods}

Age of onset was in between 4th and 36th month of life. Initial treatment consisted of physiotherapy and Chenau corrective bracing in all patients. Duration of conservative treatment was from 4 to 5.5 years. The age at surgery was: from 7 to 12 years (table 1).

Finally patients underwent surgical treatment: anterior and posterior fusion in 2 patients ( 3 curves), posterior instrumentation ( 2 growing rods) in one patient, and VEPTR device in one case. All have led to clinical improvement.

\section{Results}

In those cases the curve was rapidly progressing despite our efforts to stop it. As the conservative measures failed, we proceed to surgery for correction and stabilisation of the spine. There were no major complications during surgical treatment.

\section{Conclusions}

Conservative treatment plays a vital role in treatment of scoliosis. However, in cases of early onset and rapid progression, surgical treatment appears to be a reliable method.

Published: 27 January 2012

doi:10.1186/1748-7161-7-S1-P7

Cite this article as: Lawniczak and Kotwicki: Infantile idiopathic scoliosis: surgical treatment in rapidly progressive cases. Scoliosis 2012 7(Suppl 1): P7.

Table 1

\begin{tabular}{lllllll}
\hline Patient & $\begin{array}{l}\text { Age at } \\
\text { diagnosis in } \\
\text { years }\end{array}$ & $\begin{array}{l}\text { Curve magnitude before } \\
\text { treatment Cobb angle }\end{array}$ & $\begin{array}{l}\text { Brace } \\
\text { treatment } \\
\text { since }\end{array}$ & $\begin{array}{l}\text { Curve magnitude before } \\
\text { surgery Cobb angle }\end{array}$ & $\begin{array}{l}\text { Age at } \\
\text { surgery }\end{array}$ & $\begin{array}{l}\text { Curve magnitude at last } \\
\text { follow up Cobb angle }\end{array}$ \\
\hline 1. & 3 & 65 & 5 & 98 & 9 & 55 \\
2. & 3 & 48 & 6 & 78 & 10 & 53 \\
3.Thoracic curve & 0.5 & 47 & 1.5 & 65 & 7 & 40 \\
3.Lumbar curve & 0.5 & 44 & 1.5 & 56 & 7 & 54 \\
4. & 2 & 55 & 10 & 97 & 12 & 58 \\
\hline
\end{tabular}

Spine Disorders Unit, Department of Pediatric Orthopedics and

Traumatology, University of Medical Sciences, Poznan, Poland 